\title{
Growth hormone and risk for cardiac tumors in Carney complex
}

\author{
W Patricia Bandettini1,*, Alexander S Karageorgiadis ${ }^{2,3, *}$, Ninet Sinaii ${ }^{4}$, Douglas R \\ Rosing', Vandana Sachdev', Marie Helene Schernthaner-Reiter ${ }^{2}$, Evgenia Gourgari'2,3, \\ Georgios Z Papadakis5, Meg F Keil'2, Charalampos Lyssikatos², J Aidan Carney6, \\ Andrew E Arai', Maya Lodish² and Constantine A Stratakis²
}

${ }^{1}$ National Heart, Lung, and Blood Institute (NHLBI), National Institutes of Health (NIH), Bethesda, Maryland, USA ${ }^{2}$ National Institute of Child Health and Human Development (NICHD), NIH, Bethesda, Maryland, USA ${ }^{3}$ Department of Pediatrics, Georgetown University Hospital, Washington, District of Columbia, USA 4Biostatistics and Clinical Epidemiology Service, Clinical Center, NIH, Bethesda, Maryland, USA ${ }^{5}$ Department of Radiology and Imaging Sciences, Clinical Center, NIH, Bethesda, Maryland, USA ${ }^{6}$ Department of Laboratory Medicine and Pathology, Mayo Clinic, Rochester, Minnesota, USA *(W P Bandettini and A S Karageorgiadis contributed equally to this work)

\author{
Correspondence \\ should be addressed \\ to C A Stratakis \\ Email \\ stratakc@mail.nih.gov
}

\begin{abstract}
Carney complex (CNC) is a multiple neoplasia syndrome that is caused mostly by PRKAR1A mutations. Cardiac myxomas are the leading cause of mortality in CNC patients who, in addition, often develop growth hormone (GH) excess. We studied patients with CNC, who were observed for over a period of 20 years (1995-2015) for the development of both GH excess and cardiac myxomas. GH secretion was evaluated by standard testing; dedicated cardiovascular imaging was used to detect cardiac abnormalities. Four excised cardiac myxomas were tested for the expression of insulin-like growth factor-1 (IGF-1). A total of 99 CNC patients (97 with a PRKAR1A mutation) were included in the study with a mean age of $25.8 \pm 16.6$ years at presentation. Over an observed mean follow-up of 25.8 years, $60 \%$ of patients with $\mathrm{GH}$ excess $(n=46)$ developed a cardiac myxoma compared with only $36 \%$ of those without GH excess $(n=54)(P=0.016)$. Overall, patients with $\mathrm{GH}$ excess were also more likely to have a tumor vs those with normal GH secretion (OR: $2.78,95 \%$ $\mathrm{Cl}$ : 1.23-6.29; $P=0.014)$. IGF-1 mRNA and protein were higher in CNC myxomas than in normal heart tissue. We conclude that the development of cardiac myxomas in CNC may be associated with increased GH secretion, in a manner analogous to the association between fibrous dysplasia and GH excess in McCune-Albright syndrome, a condition similar to CNC. We speculate that treatment of GH excess in patients with CNC may reduce the likelihood of cardiac myxoma formation and/or recurrence of this tumor.
\end{abstract}
Key Words
- tumor
- acromegaly
- growth hormone
- insulin-like growth factor-I (IGF-I)
- myxoma

\section{Introduction}

Carney complex (CNC) is a multiple neoplasia syndrome that affects several organs, including the endocrine glands, heart and skin, and is caused mostly by mutations in the PRKAR1A gene, which codes for the regulatory subunit type $1 \alpha$ of the cyclic AMP-dependent protein kinase A (Stratakis et al. 2001).
The most common endocrine tumors in CNC are primary pigmented nodular adrenocortical disease (PPNAD) and growth hormone $(\mathrm{GH})$ and prolactin-producing pituitary adenomas. Antecedent somatotroph hyperplasia without overt adenoma is a common finding, whereas frank acromegaly is seen in only about $15 \%$ of the patients

Published by Bioscientifica Ltd 
(Stratakis et al. 1996, Pack et al. 2000, Watson et al. 2000). Thus, most patients with CNC exhibit modest GH excess due to dysregulation of GH secretion starting in the second decade of life, but they only rarely progress to acromegaly (Pack et al. 2000, Stergiopoulos et al. 2004).

In the heart, $\mathrm{CNC}$ is associated with the development of myxomas. These tumors are of particular concern due to the potential for thrombus development, embolization, as well as hemodynamically significant mechanical obstruction. Of additional concern is the recurrent nature of the cardiac myxomas. The operative risk of repeat cardiothoracic surgery increases as patients undergo additional surgeries with the potential for the formation of chest wall adhesions and a modified anatomy complicating cardiac access (DeLeon et al. 1986, Russell et al. 1998, Roselli 2011). Cardiac myxomas are the leading cause of disease-associated death among patients with CNC, as well as a source of significant morbidity; serial imaging of the heart is currently recommended at least annually for the early detection of primary and recurrent tumors (Stratakis et al. 2001).

A number of studies have suggested that both GH and insulin-like growth factor 1 (IGF-1), such as in patients with acromegaly, may play a role in increasing the risk for certain cancers (Ron et al. 1991, Orme et al. 1998, Jenkins et al. 1999, Jenkins \& Besser 2001, Baris et al. 2002). An analysis of almost 700 patients who underwent prospective colonoscopic screening gave an overall prevalence of colon cancer at $3.7 \%$ among patients with acromegaly (relative risk 13.4 compared with a rate of $0.5 \%$ among control subjects) (Jenkins \& Besser 2001). Epidemiological studies demonstrated an association between serum IGF-1 levels and risk of colorectal cancer (Manousos et al. 1999, Ma et al. 2000, Renehan et al. 2004). In the two largest series, comprising more than 400 patients with acromegaly, almost identical prevalence for colonic adenoma and colonic carcinoma were recorded: $23-24 \%$ of patients having a colonic adenoma and 4.3-4.5\% having cancer (Jenkins et al. 1997, Terzolo et al. 2005). A large retrospective cohort study has shown a 2.5 -fold increase in mortality from colon cancer in acromegaly vs the general population of the United Kingdom (Orme et al. 1998). Also, an increased risk for certain tumors (Giovannucci \& Pollak 2002, Raman et al. 2015) has been suggested in patients who received GH therapy in childhood for various GH deficiency states. Other studies reported increased height at a young age as a risk factor for development of malignancy at a later date (Vatten \& Kvinnsland 1990, Gunnell et al. 2001). Although these findings suggest the possible association between GH and an increased risk for certain tumors, there are no data to prove a cause-effect relationship (Jenkins et al. 2006).

At the National Institutes of Health (NIH) Clinical Research Center (CRC), a cohort of patients with CNC has been followed since 1995 (Stratakis et al. 1996, Stratakis et al. 2001). Serial cardiac imaging has been performed over the last 20 years for a subset of these patients; these patients have had frequent screening of their GH. We undertook this study to investigate the possible association between increases in GH secretion and the development of heart tumors in patients with CNC. The data show a link between the two components of the complex. This has significant implications for the care of patients with $\mathrm{CNC}$, as well as for the field of GH research.

\section{Materials and methods}

\section{Clinical studies}

The research protocol was approved by the National Institute of Child Health and Human Development (NICHD) Institutional Review Board. All participants gave written informed consent for clinical trial NCT00001452. Patients were enrolled and screened in this natural history study from 1995 to the current time. Detailed family and medical histories were obtained, and the patients underwent extensive laboratory and imaging evaluations. Data from 269 patients evaluated at the NIH Clinical center for potential CNC were retrospectively reviewed. Only patients who fulfilled the criteria for the diagnosis of $\mathrm{CNC}^{1}$ and had investigations of their $\mathrm{GH}$ secretion and heart imaging at the NIH CRC were included in this study.

Echocardiography was performed in all patients, and cardiovascular magnetic resonance imaging (MRI) in a subset of patients, as part of the patients' initial assessment and routine follow-up. In all patients, GH and IGF-1 levels were measured. All patients underwent screening in order to detect possible GH excess. This was achieved by measuring insulin-like growth factor-1 (IGF-1), GH levels after oral glucose tolerance test (OGTT) $(n=74)$ and 24-h GH levels $(n=22)$. In a subset of patients, $\mathrm{GH}$ response to thyrotropin-releasing hormone (TRH) test was measured $(n=13)$. For the evaluation of IGF-1, assay-specific age- and gender-matched normal range levels were considered. The assay for GH changed over the duration of this study as follows: From 1995 to January 1999, double antibody radioimmunoassay technique; from January 1999 to July 2012, chemiluminescence immunoassay on Immulite 2000 analyzer; from July 2012

Published by Bioscientifica Ltd 
to present, chemiluminescence immunoassay on Siemens Immulite 2000 XPI. A mean GH level of $2.5 \mu \mathrm{g} / \mathrm{L}$ and above (Ho \& Weissberger 1994, Tzanela 2006) indicated normal GH secretion. Regarding GH levels after OGTT and GH response to TRH test, nadir GH level above $1 \mu \mathrm{g} / \mathrm{L}$ and a two-fold increase in GH levels was used as an indication for GH excess, respectively (Kageyama et al. 2005, Tzanela 2006, Chin et al. 2013).

\section{Tumor studies}

IGF-1 mRNA and protein expression were tested in samples of cardiac myxomas. Four intraoperative specimens of myxomas from patients with CNC were frozen in liquid nitrogen after excision. The tumors were defrosted and lysed using a Bullet Blender homogenizer (Next Advance, Averill Park, NY, USA) in the appropriate buffer (below).

RNA was isolated with the RNEasy kit (Qiagen) including on-column DNAse I treatment. Five hundred nanograms of RNA were reverse-transcribed using Superscript III (Life Technologies), and cDNA levels were quantified in triplicate by real-time quantitative PCR (RT-qPCR) using TaqMan gene expression assays for IGF-1 along with GAPDH on a Viia Real-Time OCR system (all from Life Technologies) according to manufacturer's instructions. Normal human heart RNA pooled from three donors was obtained from Clontech.

To study protein expression, myxomas were lysed in T-PER buffer (Thermo Scientific) containing protease inhibitors (Complete, Roche). Protein

Table 1 Summary of clinical findings in the 99 study patients with Carney complex (CNC) and cardiac myxomas.

\begin{tabular}{|c|c|}
\hline Manifestations of CNC & Number of patients (\%) \\
\hline $\begin{array}{l}\text { Spotty skin pigmentation } \\
\text { (lentiginosis) }\end{array}$ & $84(84.8)$ \\
\hline Cardiac myxoma & $47(47.5)$ \\
\hline Cutaneous or mucosal myxoma & $25(25.3)$ \\
\hline Breast myxomatosis & $15(15.2)$ \\
\hline PPNAD* & $61(61.6)$ \\
\hline Acromegaly & $18(18.2)$ \\
\hline $\begin{array}{l}\text { LCCST**}^{* *} \text { or calcification on testicular } \\
\text { U/S*** }\end{array}$ & $27(27.3)$ \\
\hline $\begin{array}{l}\text { Thyroid carcinoma or multiple } \\
\text { hypoechoic nodules }\end{array}$ & $36(36.4)$ \\
\hline $\begin{array}{l}\text { Psammomatous melanotic } \\
\text { schwannoma }\end{array}$ & $11(11.1)$ \\
\hline Blue nevus & $42(42.4)$ \\
\hline Breast ductal adenoma & $2(2.0)$ \\
\hline Osteochondromyxoma & $2(2.0)$ \\
\hline
\end{tabular}

*Primary pigmented nodular adrenocortical disease; ** Large cell calcifying Sertoli cell tumor; ***U/S, ultrasound. concentrations were determined by BCA protein assay (Thermo Scientific). Normal human heart protein medley was obtained from Clontech. Ten micrograms of lysates were subjected to SDS-PAGE and Western blotting. Blots were probed using $\alpha$-IGF1 (insulin-like growth factor 1) antibody (Novus, Littleton, CO, USA) followed by $\alpha$-GAPDH (glyceraldehyde 3-phosphate dehydrogenase) antibody (Santa Cruz Biotechnology) and HRP-conjugated secondary antibodies (Jackson ImmunoResearch). Visualization was achieved by enhanced chemiluminescence on a gel imager (Bio-Rad).

\section{Statistical methods}

Data were described by frequency distributions and percents or by mean \pm standard deviation. Categorical data were compared by Fisher's exact tests or by the Jonckheere-Terpstra test for doubly ordered data. Logistic regression modeling tested the relation between GH excess and cardiac myxomas or their recurrence, adjusting for covariates as appropriate. Time to penetrance (development of event (first cardiac myxoma)) was estimated using the Kaplan-Meier survival function and is described as median (95\% confidence intervals (CIs)); differences in survival distributions between GH excess groups were compared using the log-rank test. $P$ values less than 0.05 and odds ratios (OR) with 95\% CI exclusive of 1.0 were considered statistically significant. Data analysis was carried out by SAS v. 9.2 (SAS Institute, Inc, Cary, NC, USA) or stata v. 11.2 (StataCorp, College Station, TX, USA).

\section{Role of the funding source}

The study was funded by intramural research support of the Eunice Kennedy Shriver National Institute of Child Health and Human Development. The funding source had no role in the design and conduct of the study; collection, management, analysis and interpretation of the data; or preparation, review or approval of the manuscript.

Table 2 Growth hormone (GH) evaluation in patients with CNC.

\begin{tabular}{|c|c|}
\hline Evaluation test for GH excess & $\begin{array}{l}\text { Patients with GH excess } \\
\qquad(n=46)^{\star}\end{array}$ \\
\hline Elevated GH levels after OGTT test & $30(65.3 \%)$ \\
\hline Elevated IGF-1 levels & $27(58.7 \%)$ \\
\hline Elevated GH levels after TRH test & $10(21.7 \%)$ \\
\hline Elevated 24-h GH levels & $8(17.4 \%)$ \\
\hline
\end{tabular}

*21 patients had GH excess in two or more evaluation tests.

Published by Bioscientifica Ltd 


\section{Results}

\section{Clinical and genetic epidemiology}

Ninety-nine patients fulfilled criteria for entry into study: $42(42.4 \%)$ were male. The group was predominantly white $(82.8 \%)$, with a mean age of $25.8 \pm 16.6$ years at initial evaluation at the NIH. Almost all $(n=97)$ patients had a PRKAR1A mutation. Table 1 provides a summary of findings in these patients.

\section{GH excess and cardiac myxomas}

Forty-six (46.5\%) of the 99 patients had GH excess by laboratory assessment. Thirty patients had elevated nadir GH levels after OGTT, and 27 presented with increased IGF-1 levels, matched for age and gender. In patients that were not evaluated recently for GH excess, 10 presented with elevated GH levels after TRH stimulation and 8 had increased 24-h GH levels. Twenty-one (45.7\%) had GH excess in two or more tests (Table 2).

Acromegaly was present in $18(18.2 \%)$ patients; 13 $(72.2 \%)$ had a cardiac myxoma $(P=0.0349)$. More females (29 of $57,57.6 \%$ ) had myxoma than males (18 of 42 , $42.4 \%)$, but the difference was not statistically significant ( $P=0.5417)$. Almost half of all patients $(n=47,47.5 \%)$ had a cardiac myxoma at some point within their lifetime. At their first evaluation, 33 patients (33.3\%) already had history of cardiac myxoma; 24 (24.2\% of total patients or $51.1 \%$ of those with myxomas) had recurrence of tumor.

Figure 1 illustrates the distribution of patients with and without GH excess and with and without cardiac myxoma. The majority $(n=28,60.9 \%)$ of those patients

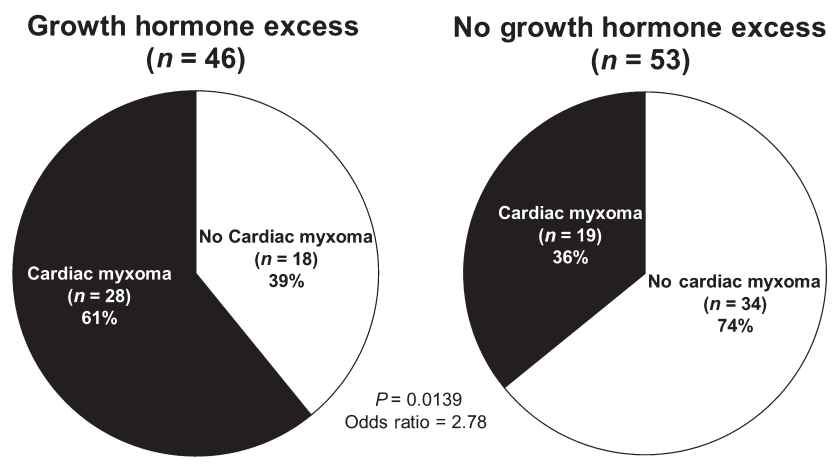

Figure 1

Cardiac myxoma and growth hormone (GH) excess in 99 patients with Carney complex (CNC): $60.9 \%$ ( $n=28$ of 46$)$ of the patients with $\mathrm{GH}$ excess had a cardiac myxoma, compared with $35.9 \%(n=19$ of 53$)$ of those who did not have $\mathrm{GH}$ excess $(P=0.0160)$. Patients with a history of $\mathrm{GH}$ excess were more likely to develop a cardiac mass versus those without $\mathrm{GH}$ excess during their lifetime (OR: $2.78,95 \% \mathrm{Cl}: 1.23-6.29, P=0.0139$ ). with a history of $\mathrm{GH}$ excess had a cardiac myxoma during their lifetime, whereas only one-third $(n=19$, $35.9 \%$ ) of those without GH excess had cardiac myxomas $(P=0.0160)$. Thus, GH excess was a statistically significant predictor of cardiac myxoma (OR: 2.78 , 95\% CI: $1.23-$ 6.29; $P=0.0139)$. Controlling for age at the time of the $\mathrm{GH}$ test did not affect the increased odds of occurrence of myxoma (OR: 2.72, 95\% CI: 1.17-6.33, $P=0.0202$ ). Although patients with GH excess also tended to have more recurrent myxomas (30.4\% vs $18.9 \%)$ the difference was not statistically significant $(P=0.2405)$. However, when we evaluated the absolute number of myxomas occurring within the period of observation, 23 of 47 patients (48.9\%) had a single myxoma, 12 (25.5\%) had two myxomas, 9 (19.2\%) had three myxomas, 1 (2.1\%) had four myxomas, and 2 (4.3\%) patients had greater than five myxomas. Indeed, patients with the highest number of cardiac myxomas were those with GH excess $(P=0.0154)$.

\section{Age, cardiac myxomas and GH excess}

The median time to detection of a patient's initial cardiac myxoma was 34.5 years (95\% CI: $31.5-45.2$ years). Over the observed duration of 65.3 years of follow-up (mean 25.8 years), the Kaplan-Meier survivor function estimated up to $25 \%$ chance of having a cardiac mass by age 25.3 years, a $50 \%$ chance by 34.5 years and a $75 \%$ chance

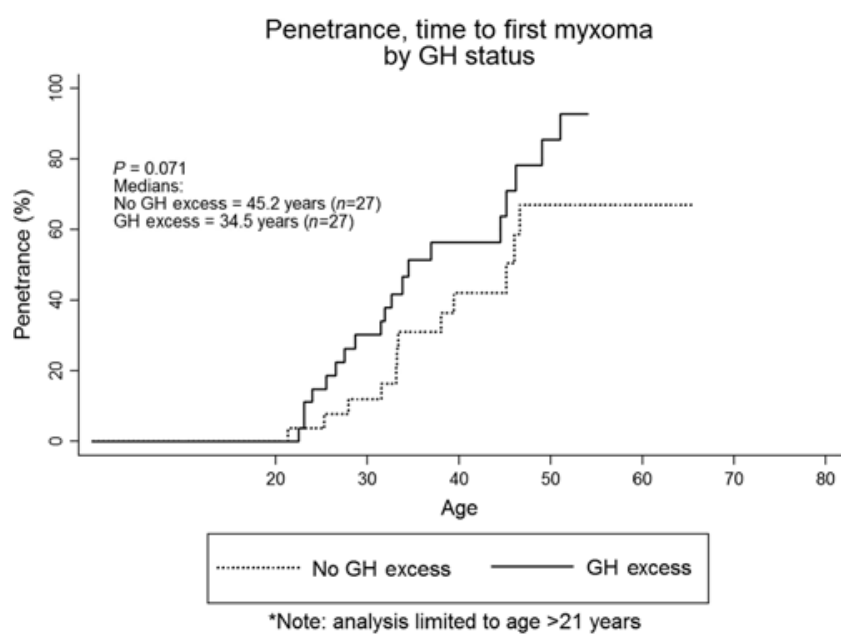

Figure 2

Kaplan-Meier curve of penetrance (time to first myxoma) grouped by presence or absence of growth hormone $(\mathrm{GH})$ excess, restricted to those age 21 or older at the time of GH testing. Those with GH excess had a median time to first myxoma of 34.5 years ( $95 \% \mathrm{Cl}: 28.7-46.2)$ compared with 45.2 years ( $95 \% \mathrm{Cl}$ : 33.4 -(undefined upper bound)) in those without $\mathrm{GH}$ excess $(P=0.0709)$.

Published by Bioscientifica Ltd. 
by 46.6 years. In those patients with GH excess, the median time to penetrance was 32.6 years (95\% CI: $26.5-$ 44.5). The median time to penetrance in those without GH excess was 39.4years (95\% CI: 33.1-46.6). While there may be a modest earlier manifestation in those with $\mathrm{GH}$ excess, the finding was not statistically significant $(P=0.1061)$. The median time to presentation with a myxoma was also compared between patients with CNC and GH excess before and after the age of 21 years: those with GH excess had a median time to first myxoma of 34.5 years (95\% CI: $28.7-46.2$ ) compared with 45.2 years (95\% CI: 33.4-(undefined upper bound)) in those without GH excess $(P=0.0709)$ (Fig. 2).

\section{GH signaling in CNC}

In vitro analysis of IGF-1/GAPDH-relative mRNA expression in four cardiac myxomas from separate patients was performed. IGF-1 expression was found to be upregulated in myxomas at the mRNA and protein levels, when compared with pooled normal heart tissue (3 donors) $(P=0.002)$ (Fig. 3).

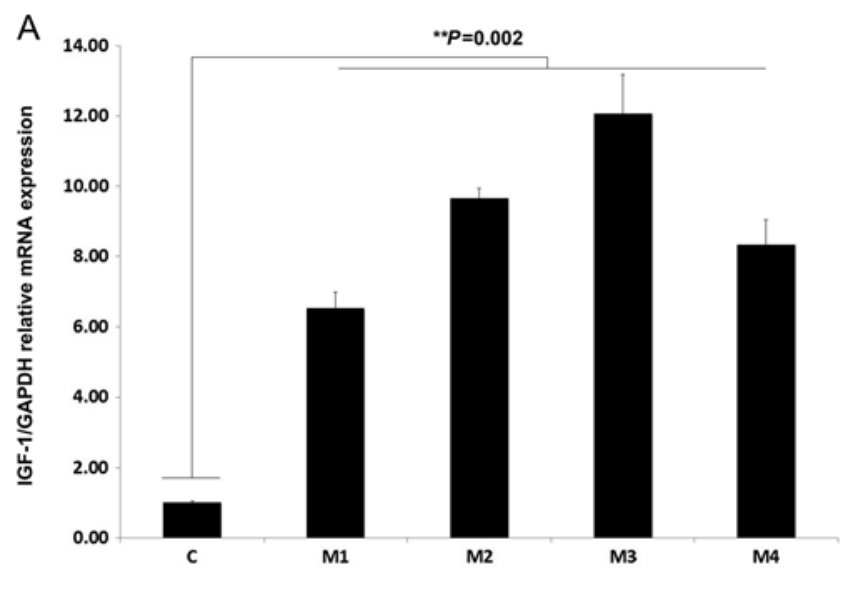

$\begin{array}{llllll}\text { B } & \text { C } & \text { M1 } & \text { M2 } & \text { M3 } & \text { M4 }\end{array}$

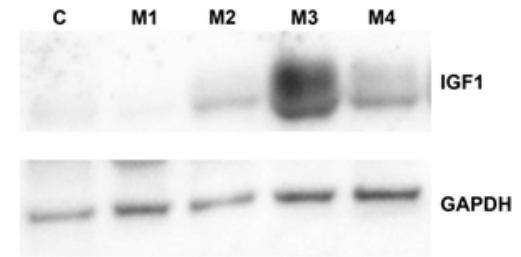

Figure 3

IGF-1 mRNA and protein expression in cardiac myxomas. Samples were four different CNC-associated cardiac myxomas (M1-M4) and normal control heart (C). (A) IGF-1 mRNA expression levels were determined by RT-qPCR performed in triplicate. Error bars represent the S.E.M. and show that IGF-1 expression is clearly upregulated in myxomas on the mRNA $(P=0.002)$. (B) Western blotting showing the protein expression of IGF-1.

\section{Treatment for acromegaly and myxomas}

Of the 46 patients with GH excess, 9 (19.6\%) underwent transsphenoidal surgery for removal of pituitary adenoma, 1 (2.2\%) received radiation therapy and 5 (10.9\%) had medical therapy (somatostatin analogs or dopamine agonists). There were 10 patients $(21.7 \%)$ that had to have a combination of these treatments because of aggressive acromegaly that did not respond to previous therapeutic attempts; of these, 8 had a cardiac myxoma, a difference that was also significant $(P=0.0438) ; 2$ had recurrent myxoma.

\section{Discussion}

This study represents the first report of an association between excess $\mathrm{GH}$ and increased risk of cardiac myxomas in patients with CNC. The differences between CNC patients with GH excess and those without GH excess were striking: $60.9 \%$ of patients with GH excess had a cardiac myxoma versus $35.9 \%$ of the patients without GH excess. Certainly, not all cardiac myxomas in CNC patients can be attributed to GH excess, as evidenced by the number of patients with cardiac myxoma in the absence of elevated GH levels. However, GH excess appears to be the only significant risk factor, in addition to the underlying disease, for the development of the cardiac myxoma in patients with CNC.

This finding has significant clinical implications for a potential therapeutic target to decrease myxoma occurrence, i.e. those patients with $\mathrm{CNC}$ and excess $\mathrm{GH}$ may need earlier and/or more aggressive treatment of hypersomatotropinemia. It should be noted, however, that although our data confirm that CNC patients with frank acromegaly who required treatment for their condition had a higher number of cardiac tumor recurrences, only one patient received treatment for acromegaly preceding myxoma development. Thus, we do not know if treatment will alter the likelihood of developing myxomas. Interestingly, the recent paper by Chesnokova and coworkers found that using pegvisomant to block colon cell GH receptors in vitro and in patients with acromegaly increased p53 expression, thus suggesting that blocking GH signaling may yield tumor-protective effects (Chesnokova et al. 2016).

This study is also the first to report the lifetime prevalence of cardiac myxoma in CNC patients with a $25 \%$ risk of developing the tumor by the age of 25 and an increasing risk of developing cardiac myxoma over time. What causes the myxomas remains unclear. Almost all

Published by Bioscientifica Ltd 
(97 out of 99) of our patients had a PRKAR1A mutation, which is a slightly higher percentage than previously reported (Bertherat et al. 2009, Horvath et al. 2010). PRKAR1A is a tumor-suppressor gene whose inactivation causes tumors in mice (Kirschner et al. 2005) and abnormal growth and proliferation of human cells in vitro (Nadella et al. 2008, Nesterova et al. 2008). In addition, inactivation of the gene in murine cardiac tissue leads to myxomatous lesions (Yin et al. 2008).

Gender does not appear to play a role in CNC-related myxomas (Carney 1985). Although more than $75 \%$ of sporadic cardiac myxomas occur in females (Bjessmo \& Ivert 1997, Zheng et al. 2013), this study, in accordance with older data in CNC (Carney 1985), did not show a higher prevalence of myxomas among female patients with CNC. Likewise, GH elevation did not have a different effect in male versus female patients with CNC (data not shown).

Our study does not suggest that GH is a factor in the first molecular events that are needed for the formation of cardiac myxoma, but it does implicate GH and/or IGF-1 in the facilitation of new tumor formation or growth. In the cardiac myxomas we studied after surgical removal, IGF-1 was upregulated compared with normal heart tissue (Fig. 3). GH and/or IGF-1 can promote neoplastic growth of various cell types. However, there is controversy regarding the effect of exogenous GH treatment (Renehan et al. 2004, Raman et al. 2015). Perhaps the best example of increased endogenous GH and/or IGF1 associated with growth of a neoplasm in the context of a multiple neoplasia disorder is that of fibrous dysplasia in patients with McCune-Albright syndrome (MAS) and hypersomatotropinemia (Boyce et al. 2013). Also, bone sarcoma in MAS may be associated with excess GH and/or IGF-1 (Salenave et al. 2014).

It is unclear whether our findings have implications for the sporadic cardiac myxoma. In autopsy studies, myxoma is the most common primary cardiac tumor found, accounting for one-half of all postmortem benign cardiac tumors (McAllister \& Fenoglio 1978). It would be interesting to study the GH and/or IGF-1 levels of patients with sporadic myxomas, as well as possible co-occurrence with other tumors, especially those of organs that have been linked to GH and/or IGF-1.

In conclusion, excess GH has a significantly increased risk of cardiac myxoma in patients with $\mathrm{CNC}$. GH excess may be playing an augmentative role in the growth of cardiac myxoma; however, other additional factors likely contribute as $36 \%$ of patients without GH excess were found to have cardiac myxoma. This association poses the important clinical question of whether or not early identification and treatment of GH excess in patients with CNC will reduce morbidity and mortality from cardiac myxomas. The time course of the development of cardiac myxoma in CNC underscores the need for affected patients to undergo cardiac surveillance imaging, starting at a young age and continuing indefinitely.

Declaration of interest

The authors have no conflicts of interest related to the manuscript to report. Dr Schernthaner-Reiter reports personal fees from Boehringer Ingelheim, outside the submitted work. Unrelated to the submitted work, Dr Arai has a U.S. Government Cooperative Research and Development Agreement (CRADA) with Siemens. Dr Stratakis also holds patents not directly related to the submission.

\section{Funding}

Intramural research support of the Eunice Kennedy Shriver National Institute of Child Health and Human Development.

\section{Author contribution statement}

Drs Stratakis and Lodish had full access to all of the data in the study and take responsibility for the integrity of the data and the accuracy of the data analysis. Arai, Lodish, Stratakis and Carney performed study concept and design. Bandettini, Karageorgiadis, Lodish, Sinaii, SchernthanerReiter, Gourgari, Papadakis and Lyssikatos performed acquisition, analysis or interpretation of data. Bandettini, Karageorgiadis, Sinaii, Lodish, Stratakis and Schernthaner-Reiter performed drafting of the manuscript. Bandettini, Karageorgiadis, Sinaii, Rosing, Sachdev, Schernthaner-Reiter, Gourgari, Papadakis, Keil, Lyssikatos, Carney, Arai, Lodish and Stratakis performed critical revision of the manuscript for important intellectual content. Sinaii performed statistical analysis. Sachdev, SchernthanerReiter, Gourgari, Papadakis, Keil and Lyssikatos administrative, technical or material support. Arai, Stratakis and Rosing performed study supervision.

\section{Acknowledgements}

We thank all of the Carney complex patients and their families who participated in this study. We also thank Megan Monroe, PhD, for allowing us to use her EventFlow Visualization software in our initial data analysis.

\section{References}

Baris D, Gridley G, Ron E, Weiderpass E, Mellemkjaer L, Ekbom A, Olsen JH, Baron JA \& Fraumeni JF Jr 2002 Acromegaly and cancer risk: a cohort study in Sweden and Denmark. Cancer Causes \& Control 13 395-400. (doi:10.1023/A:1015713732717)

Bertherat J, Horvath A, Groussin L, Grabar S, Boikos S, Cazabat L, Libe R, Rene-Corail F, Stergiopoulos S, Bourdeau I, et al. 2009 Mutations in regulatory subunit type $1 \mathrm{~A}$ of cyclic adenosine 5'-monophosphate-dependent protein kinase (PRKAR1A): phenotype analysis in 353 patients and 80 different genotypes. Journal of Clinical Endocrinology and Metabolism 94 2085-2091. (doi:10.1210/jc.2008-2333)

Bjessmo S \& Ivert T 1997 Cardiac myxoma: 40 years' experience in 63 patients. Annals of Thoracic Surgery 63 697-700. (doi:10.1016/ S0003-4975(96)01368-9) 
Boyce AM, Glover M, Kelly MH, Brillante BA, Butman JA, Fitzgibbon EJ, Brewer CC, Zalewski CK, Cutler Peck CM, Kim HJ, et al. 2013 Optic neuropathy in McCune-Albright syndrome: effects of early diagnosis and treatment of growth hormone excess. Journal of Clinical Endocrinology and Metabolism 98 E126-E134. (doi:10.1210/ jc.2012-2111)

Carney JA 1985 Differences between nonfamilial and familial cardiac myxoma. American Journal of Surgical Pathology 9 53-55. (doi:10.1097/00000478-198501000-00009)

Chesnokova V, Zonis S, Zhou C, Recouvreux MV, Ben-Shlomo A, Araki T, Barrett R, Workman M, Wawrowsky K, Ljubimov VA, et al. 2016 Growth hormone is permissive for neoplastic colon growth. PNAS 113 E3250-E3259. (doi:10.1073/pnas.1600561113)

Chin SO, Rhee SY, Chon S, Hwang YC, Jeong IK, Oh S \& Kim SW 2013 Investigation of responsiveness to thyrotropin-releasing hormone in growth hormone-producing pituitary adenomas. International Journal of Endocrinology 2013 159858. (doi:10.1155/2013/159858)

DeLeon SY, LoCicero J 3rd, Ilbawi MN \& Idriss FS 1986 Repeat median sternotomy in pediatrics: experience in 164 consecutive cases. Annals of Thoracic Surgery 41 184-188. (doi:10.1016/S0003-4975(10)62665-3)

Giovannucci E \& Pollak M 2002 Risk of cancer after growth-hormone treatment. Lancet 360 268-269. (doi:10.1016/S0140-6736(02) 09561-2)

Gunnell D, Okasha M, Smith GD, Oliver SE, Sandhu J \& Holly JM 2001 Height, leg length, and cancer risk: a systematic review. Epidemiologic Reviews 23 313-342. (doi:10.1093/oxfordjournals.epirev.a000809)

Ho KY \& Weissberger AJ 1994 Characterization of 24-hour growth hormone secretion in acromegaly: implications for diagnosis and therapy. Clinical Endocrinology 41 75-83. (doi:10.1111/j.1365-2265. 1994.tb03787.x)

Horvath A, Bertherat J, Groussin L, Guillaud-Bataille M, Tsang K, Cazabat L, Libe R, Remmers E, Rene-Corail F, Faucz FR, et al. 2010 Mutations and polymorphisms in the gene encoding regulatory subunit type 1-alpha of protein kinase A (PRKAR1A): an update. Human Mutation 31 369-379. (doi:10.1002/humu.21178)

Jenkins PJ \& Besser M 2001 Clinical perspective: acromegaly and cancer: a problem. Journal of Clinical Endocrinology and Metabolism $\mathbf{8 6}$ 2935-2941. (doi:10.1210/jcem.86.7.7634)

Jenkins PJ, Fairclough PD, Richards T, Lowe DG, Monson J, Grossman A, Wass JA \& Besser M 1997 Acromegaly, colonic polyps and carcinoma. Clinical Endocrinology 47 17-22. (doi:10.1046/j.1365-2265.1997.1911029.x)

Jenkins PJ, Besser GM \& Fairclough PD 1999 Colorectal neoplasia in acromegaly. Gut 44 585-587. (doi:10.1136/gut.44.5.585)

Jenkins PJ, Mukherjee A \& Shalet SM 2006 Does growth hormone cause cancer? Clinical Endocrinology 64 115-121. (doi:10.1111/ j.1365-2265.2005.02404.x)

Kageyama K, Moriyama T, Sakihara S, Takayasu S, Nigawara T \& Suda T 2005 Usefulness of the thyrotropin-releasing hormone test in preclinical acromegaly. Tohoku Journal of Experimental Medicine 206 291-297. (doi:10.1620/tjem.206.291)

Kirschner LS, Kusewitt DF, Matyakhina L, Towns WH 2nd, Carney JA, Westphal H \& Stratakis CA 2005 A mouse model for the Carney complex tumor syndrome develops neoplasia in cyclic AMP-responsive tissues. Cancer Research 65 4506-4514. (doi:10.1158/ 0008-5472.CAN-05-0580)

Ma J, Pollak M, Giovannucci E, Chan JM, Tao Y, Hennekens C \& Stampfer MJ 2000 A prospective study of plasma levels of insulin-like growth factor I (IGF-I) and IGF-binding protein-3, and colorectal cancer risk among men. Growth Hormone \& IGF Research 10 (Supplement A) S28-S29. (doi:10.1016/s1096-6374(00) 90013-3)

Manousos O, Souglakos J, Bosetti C, Tzonou A, Chatzidakis V, Trichopoulos D, Adami HO \& Mantzoros C 1999 IGF-I and IGF-II in relation to colorectal cancer. International Journal of Cancer 83 15-17. (doi:10.1002/(sici)1097-0215(19990924)83:1<15::aid-ijc4>3.0.co;2-y)
McAllister HA Jr \& Fenoglio JJ Jr 1978 Tumors of the Cardiovascular System. Atlas of Tumor Pathology, 2nd series. Fascicle 15. Washington, DC, USA: Armed Forces Institute of Pathology.

Nadella KS, Jones GN, Trimboli A, Stratakis CA, Leone G \& Kirschner LS 2008 Targeted deletion of Prkar1a reveals a role for protein kinase A in mesenchymal-to-epithelial transition. Cancer Research $\mathbf{6 8}$ 2671-2677. (doi:10.1158/0008-5472.CAN-07-6002)

Nesterova M, Bossis I, Wen F, Horvath A, Matyakhina L \& Stratakis CA 2008 An immortalized human cell line bearing a PRKAR1Ainactivating mutation: effects of overexpression of the wild-type Allele and other protein kinase A subunits. Journal of Clinical Endocrinology and Metabolism 93 565-571. (doi:10.1210/jc.2007-1902)

Orme SM, McNally RJ, Cartwright RA \& Belchetz PE 1998 Mortality and cancer incidence in acromegaly: a retrospective cohort study. United Kingdom Acromegaly Study Group. Journal of Clinical Endocrinology and Metabolism 83 2730-2734. (doi:10.1210/jc.83.8.2730)

Pack SD, Kirschner LS, Pak E, Zhuang Z, Carney JA \& Stratakis CA 2000 Genetic and histologic studies of somatomammotropic pituitary tumors in patients with the "complex of spotty skin pigmentation, myxomas, endocrine overactivity and schwannomas" (Carney complex). Journal of Clinical Endocrinology and Metabolism $\mathbf{8 5}$ 3860-3865. (doi:10.1210/jcem.85.10.6875)

Raman S, Grimberg A, Waguespack SG, Miller BS, Sklar CA, Meacham LR \& Patterson BC 2015 Risk of neoplasia in pediatric patients receiving growth hormone therapy - a report from the Pediatric Endocrine Society Drug and Therapeutics Committee. Journal of Clinical Endocrinology and Metabolism 100 2192-2203. (doi:10.1210/ jc.2015-1002)

Renehan AG, Zwahlen M, Minder C, O'Dwyer ST, Shalet SM \& Egger M 2004 Insulin-like growth factor (IGF)-I, IGF binding protein-3, and cancer risk: systematic review and meta-regression analysis. Lancet 363 1346-1353. (doi:10.1016/S0140-6736(04)16044-3)

Ron E, Gridley G, Hrubec Z, Page W, Arora S \& Fraumeni JF Jr 1991 Acromegaly and gastrointestinal cancer. Cancer 68 1673-1677. (doi:10.1002/1097-0142(19911015)68:8<1673::aidcncr2820680802>3.0.co;2-0)

Roselli EE 2011 Reoperative cardiac surgery: challenges and outcomes Texas Heart Institute Journal 38 669-671.

Russell JL, LeBlanc JG, Sett SS \& Potts JE 1998 Risks of repeat sternotomy in pediatric cardiac operations. Annals of Thoracic Surgery 66 1575-1578. (doi:10.1016/S0003-4975(98)00829-7)

Salenave S, Boyce AM, Collins MT \& Chanson P 2014 Acromegaly and McCune-Albright syndrome. Journal of Clinical Endocrinology and Metabolism 99 1955-1969. (doi:10.1210/jc.2013-3826)

Stergiopoulos SG, Abu-Asab MS, Tsokos M \& Stratakis CA 2004 Pituitary pathology in Carney complex patients. Pituitary 7 73-82. (doi:10.1007/s11102-005-5348-y)

Stratakis CA, Carney JA, Lin JP, Papanicolaou DA, Karl M, Kastner DL, Pras E \& Chrousos GP 1996 Carney complex, a familial multiple neoplasia and lentiginosis syndrome. Analysis of 11 kindreds and linkage to the short arm of chromosome 2. Journal of Clinical Investigation 97 699-705. (doi:10.1172/JCI118467)

Stratakis CA, Kirschner LS \& Carney JA 2001 Clinical and molecular features of the Carney complex: diagnostic criteria and recommendations for patient evaluation. Journal of Clinical Endocrinology and Metabolism 86 4041-4046. (doi:10.1210/jcem.86.9.7903)

Terzolo M, Reimondo G, Gasperi M, Cozzi R, Pivonello R, Vitale G, Scillitani A, Attanasio R, Cecconi E, Daffara F, et al. 2005 Colonoscopic screening and follow-up in patients with acromegaly: a multicenter study in Italy. Journal of Clinical Endocrinology and Metabolism 90 84-90. (doi:10.1210/jc.2004-0240)

Tzanela M 2006 Dynamic tests and basal values for defining active acromegaly. Neuroendocrinology 83 200-204. (doi:10.1159/000095528)

Vatten LJ \& Kvinnsland S 1990 Body height and risk of breast cancer. A prospective study of 23,831 Norwegian women. British Journal of Cancer 61 881-885. (doi:10.1038/bjc.1990.197) http://erc.endocrinology-journals.org

DOI: 10.1530/ERC-16-0246
○ 2016 Society for Endocrinology Printed in Great Britain 
Watson JC, Stratakis CA, Bryant-Greenwood PK, Koch CA, Kirschner LS, Nguyen T, Carney JA \& Oldfield EH 2000 Neurosurgical implications of Carney complex. Journal of Neurosurgery 92 413-418. (doi:10.3171/ jns.2000.92.3.0413)

Yin Z, Jones GN, Towns WH 2nd, Zhang X, Abel ED, Binkley PF, Jarjoura D \& Kirschner LS 2008 Heart-specific ablation of Prkar1a causes failure of heart development and myxomagenesis. Circulation 117 1414-1422. (doi:10.1161/CIRCULATIONAHA.107.759233) Zheng JJ, Geng XG, Wang HC, Yan Y \& Wang HY 2013 Clinical and histopathological analysis of 66 cases with cardiac myxoma. Asian Pacific Journal of Cancer Prevention 14 1743-1746. (doi:10.7314/ APJCP.2013.14.3.1743)

Received in final form 8 July 2016

Accepted 15 July 2016

Accepted Preprint published online 18 July 2016 